\title{
Hypoxia-induced PGC-1 $\alpha$ Regulates Mitochondrial Function and Tumorigenesis of Colorectal Cancer Cells
}

\author{
CHUL WON YUN ${ }^{1}$, JUN HEE LEE $^{1,2}$ and SANG HUN LEE ${ }^{1,2}$ \\ ${ }^{1}$ Medical Science Research Institute, Soonchunhyang University Seoul Hospital, Seoul, Republic of Korea; \\ ${ }^{2}$ Departments of Biochemistry, Soonchunhyang University College of Medicine, Cheonan, Republic of Korea
}

\begin{abstract}
Background/Aim: Hypoxia promotes tumor proliferation and metastasis in colorectal cancer (CRC). Since the tumor microenvironment is generally characterized by hypoxia, its understanding is important for cancer therapy. We hypothesized that hypoxia promotes the mitochondrial function, mobility, and proliferation of CRC by up-regulating peroxisome proliferator-activated receptor gamma coactivator 1-alpha (PGC-1 $\alpha)$. Materials and Methods: To assess the effects of PGC-1 $\alpha$ under hypoxia, we investigated the mitochondrial function, cell motility, and sphere formation as well as proliferation and apoptosis of CRC. Results: Under hypoxia, we confirmed the increased expression of $P G C-1 \alpha$ and reduced production of reactive oxygen species (ROS) by activating anti-oxidant enzymes. Also, up-regulation of PGC-1 $\alpha$ enhanced the motility, sphere formation, and proliferation of CRC. Under the presence of the anti-cancer drug 5-fluorouracil (5FU), up-regulation of $P G C-1 \alpha$ under hypoxia promoted resistance of CRC against 5FU-induced apoptosis. Conclusion: Targeting PGC-1 $\alpha$ could to be a powerful strategy for CRC therapy.
\end{abstract}

Colorectal cancer (CRC) is a major health concern and one of the leading causes of cancer-related deaths in the world. Although cancer therapeutic methods including surgical skills, tumor molecule targeting, and chemotherapy, have drastically improved, therapeutic efficacy for cancer is still limited because of undefined mechanisms underlying cancer metastasis and recurrence. CRC is linked with several risk factors such as age, diet, smoking, and alcohol consumption. It is generally characterized by the up-regulation of oncogenes

Correspondence to: Sang Hun Lee, Ph.D., Medical Science Research Institute, Soonchunhyang University Seoul Hospital, Seoul, Korea and Departments of Biochemistry, Soonchunhyang University College of Medicine, Cheonan, Republic of Korea. Tel: +82 27099029, e-mail: ykckss1114@ nate.com,jhlee0407@sch.ac.kr

Key Words: Colorectal cancer, hypoxia, PGC-1 $\alpha$, mitochondrial biogenesis, proliferation, apoptosis. and down-regulation of tumor suppressor genes via mutations; this results in the growth of CRC into an invasive tumor (1). In the context of the tumor microenvironment, cancer is often characterized by hypoxia and inflammation (2). Therefore, regulation of oncogenes and tumor suppressor genes and the control of the tumor microenvironment are one of the powerful strategies for treating CRC.

Homeostasis for oxygen level is important for the maintenance of organisms under physiological as well as pathophysiological conditions (3). Hypoxia, which is an environment with restricted oxygen availability, is a characteristic of the tumor microenvironment during tumorigenesis. Hypoxia plays a pivotal role in cancer through the alteration of microenvironment, changes in oncogenes expression, reprogramming of metabolism, and formation of non-functional blood vessels, thus, resulting in the induction of metastasis $(4,5)$. Hypoxia induces cancer cell proliferation, development of aggressive tumor phenotype, and anti-cancer drug resistance $(6,7)$. These effects of hypoxia are regulated by hypoxia inducible factor (HIF), which is a master gene in cancer physiology; it controls the expression of oncogene transcription factors and relevant target genes as well as cancer cell metabolism $(8,9)$. However, since HIF protein regulates various down-stream pathways vital for cell physiology, it is important to investigate HIF-mediated specific target protein/s for cancer survival.

Peroxisome proliferator-activated receptor $\gamma$ coactivator- $1 \alpha$ (PGC-1 $\alpha$ ) is known as a central regulator of cell metabolism (10). PGC-1 $\alpha$, the first member of the PGC-1 family, is a transcriptional coactivator for peroxisome proliferator-activated receptor $\gamma(\operatorname{PPAR} \gamma)$ and plays roles in thermogenesis, muscle fiber regeneration, mitochondrial biogenesis, fatty acid oxidation, triglyceride metabolism, and lipogenesis (10). In particular, PGC-1 $\alpha$, as a master regulator of metabolism, controls energy metabolism such as mitochondrial oxidative phosphorylation, mitochondrial biogenesis, and glucose metabolism. Overexpression of PGC- $1 \alpha$ increases the amount of mitochondrial DNA, which encodes several protein subunits of the mitochondrial respiratory chain $(10,11)$. PGC- $1 \alpha$ induces fatty acid transporter CD36 and carnitine palmitoyltransferase 
1 (CPT1), which are key factors for fatty acid oxidation (12). Furthermore, PGC-1 $\alpha$ protects against ROS-induced cell death through the up-regulation of antioxidant enzymes (13). Several studies have indicated that PGC- $1 \alpha$, in cancer cells, plays a role in response to numerous stresses and environmental conditions, leading to reprograming of the metabolism, anti-oxidant effect against radiation and chemotherapy as well as metastasis by crosstalk between adipocytes and cancer cells $(10,14,15)$. To determine the relation between hypoxia and PGC-1 $\alpha$ in CRC cells, herein, we have investigated the expression of PGC- $1 \alpha$ in CRC cells under hypoxic conditions. Furthermore, to examine whether PGC- $1 \alpha$ regulates the mitochondrial biogenesis, mitochondrial oxidative phosphorylation, invasion, tumorigenesis, proliferation, and drug resistance in CRC cells under hypoxic conditions, we assessed the effect of PGC- $1 \alpha$ in CRC cells under hypoxia.

\section{Materials and Methods}

Preparation of fluorouracil ( $5 \mathrm{FU}$ ). 5FU was purchased from Sigma (St. Louis, MO, USA) and dissolved in DMSO at $10 \mathrm{mM}$ concentration. Stock solution was filter-sterilized using a $0.22 \mu \mathrm{m}$ pore filter (Sartorius Biotech $\mathrm{GmbH}$, Gottingen, Germany). Aliquots of stock solution were stored at $4^{\circ} \mathrm{C}$.

Cell culture. The human CRC cell lines (SNU-C5/WT) were acquired from the Chosun University Research Center for Resistant Cells (Gwangju, Republic of Korea). The cells were cultured in RPMI 1640 (GE Healthcare Life Science, MA, USA) supplemented with $10 \%$ fetal bovine serum (GE Healthcare Life Science) and antibiotics (Biological Industries, Beit Haemek, Israel) at $37^{\circ} \mathrm{C}$ with $5 \% \mathrm{CO}_{2}$ in a humidified incubator.

Inhibition of PGC-1 $\alpha$ expression by RNA interference (siRNA). SNUC5/WT cells were transfected with siRNA in serum-free Opti-MEM (Gibco BRL) by utilizing Lipofectamine 2000 (Thermo Fisher Scientific, Waltham, MA, USA), following the manufacturer's instructions. Following the transfection with siRNA for $48 \mathrm{~h}$, cells were treated with 5FU under normoxic or hypoxic conditions for 24 $\mathrm{h}$. The siRNA ordered to block PGC- $1 \alpha$ (The PGC- $1 \alpha$ siRNA no. 1 sequence: 5'-UCACCGAGACCGACGUUAA-3', no. 2 sequence: 5'GAUCGAGCAUGGUCCUCUU-3', no. 3 sequence: 5'-AGAUGU GUAUCACCCAGUA-3', and no. 4 sequence: 5'-GACCGUUAC UAUCGUGAAA-3') and a scrambled sequence (The scrambled siRNA no. 1 sequence: 5'-UGGUUUACAUGUCGACUAA-3', no. 2 sequence: 5'-UGGUUUACAUGUUGUGUGA-3', no. 3 sequence: 5'UGGUUUACAUGUUUUCUGA-3', and no. 4 sequence: 5'UGGUUUACAUGUUUUCCUA-3') were purchased from Dharmacon (Lafayette, CO, USA).

Western blot analysis. Total cell protein lysates were isolated using RIPA buffer (Thermo Fisher Scientific). Protein lysates were separated by sodium dodecyl sulfate-polyacrylamide gel electrophoresis. Proteins were transferred to polyvinylidene fluoride membranes (PVDF; Millipore, Billerica, MA, USA). The membranes were blocked with $5 \%$ skim milk for $1 \mathrm{~h}$ with constant stirring and subsequently incubated with primary antibodies against PGC- $1 \alpha$ (Santa Cruz Biotechnology, Dallas, TX, USA), phospho-dynamin- related protein 1 (p-DRP1; Cell Signaling Technology, MA, USA), mitofusin-1 (MFN1; Cell signaling Technology), optic atrophy 1 (OPA1; Cell Signaling Technology), cyclin-dependent kinase 2 (CDK2; Santa Cruz Biotechnology), CDK4 (Santa Cruz Biotechnology), cyclin D1 (Santa Cruz Biotechnology), cyclin E (Santa Cruz Biotechnology), B-cell lymphoma 2 (BCL2; Santa Cruz Biotechnology), Bcl-2-associated X protein (BAX; Santa Cruz Biotechnology), cleaved caspase-3 (Santa Cruz Biotechnology), cleaved poly[ADP-ribose] polymerase 1 (PARP1; Santa Cruz Biotechnology), and $\beta$-actin (Santa Cruz Biotechnology). Following incubation, the PVDF membranes were washed with TBST $(10 \mathrm{mM}$ Tris- $\mathrm{HCl}$ [pH 7.6], $150 \mathrm{mM} \mathrm{NaCl}$, and $0.05 \%$ Tween-20), and then incubated with peroxidase-conjugated goat anti-mouse or anti-rabbit IgG secondary antibodies (Thermo Fisher Scientific). The visualization of protein bands was carried out using enhanced chemiluminescence reagents (Amersham Biosciences, Uppsala, Sweden).

Immunofluorescence staining. SNU-C5/WT cells were grown on cover glass coverslips. The cells were cultured under hypoxic conditions for $24 \mathrm{~h}$. After fixing the cells using 4\% paraformaldehyde, they were incubated with primary antibodies against PGC-1 $\alpha$ (Santa Cruz Biotechnology), and then subsequently incubated with secondary antibodies conjugated with Alexa Fluor 488 (Thermo Fisher Scientific). Nuclei were stained with 4',6diamidino-2-phenylindole (DAPI; Sigma). Stained slides were imaged using a confocal microscope (Leica, Wetzlar, Germany).

Measurement of mitochondrial DNA using Quantitative Real-Time $P C R$ ( $q R T-P C R$ ). The qRT-PCR analysis was performed using the Maxima SYBR Green/ROX qPCR Master Mix (Thermo Fisher Scientific). The qRT-PCR reaction using the StepOnePlus RealTime PCR system (Thermo Fisher Scientific) was performed under cycling conditions of $95^{\circ} \mathrm{C}$ for $45 \mathrm{sec}$ (denaturation), $61^{\circ} \mathrm{C}$ for 45 sec (annealing), and $72^{\circ} \mathrm{C}$ for $60 \mathrm{sec}$ (extension), for 40 cycles. The gene expression level normalized to $\beta$-actin was calculated using the $\Delta \Delta \mathrm{Ct}$ method with reference to the normoxic SNU-C5/WT. The primer sequences were as follows: mtDNA tRNA forward, 5'CACCCAAGAACAGGGTTTGT-3'; mtDNA tRNA reverse, 5'TGGCCATGGGTATGTTGTTA-3'; gDNA $\beta 2$-microglobulin forward, 5'-TGCTGTCTCCATGTTTGATGTATCT-3'; gDNA $\beta 2$ microglobulin reverse, 5'-TCTCTGCTCCCCACCTCTAAGT-3'; $\beta$ actin forward, 5'-AACCGCGAGAAGATGACC- 3'; $\beta$-actin reverse, 5'-AGCAGCCGTGGCCATCTC-3'.

Flow cytometry analysis. To evaluate the generation of mitochondrial ROS, SNU-C5/WT cells were stained with MitoSOX ${ }^{\mathrm{TM}}$ Red staining reagent (Thermo Fisher Scientific) for $30 \mathrm{~min}$ at $37^{\circ} \mathrm{C}$ and washed with phosphate-buffered saline. To analyze the cell cycle, cells were incubated with RNase and stained with propidium iodide (PI; Thermo Fisher Scientific). To assess apoptosis, cells were stained with Annexin V-fluorescein isothiocyanate (FITC) and propidium iodide (PI) (Thermo Fisher Scientific). Each sample was quantitatively analyzed by a CyFlow Cube 8 (Sysmex Partec, Münster, Germany). Data analysis was carried out using the FCS Express software package (De Novo Software, Los Angeles, CA, USA).

Analysis of the activities of mitochondrial complex I and IV. The mitochondrial fractions $(0.6 \mathrm{mg} / \mathrm{ml})$ were obtained by incubating for $3 \mathrm{~min}$ in a mitochondrial extraction buffer $(250 \mathrm{mM}$ sucrose, $50 \mathrm{mM}$ potassium-phosphate, $1 \mathrm{mM} \mathrm{KCN}, 50 \mu \mathrm{M}$ decylubiquinone, 
A

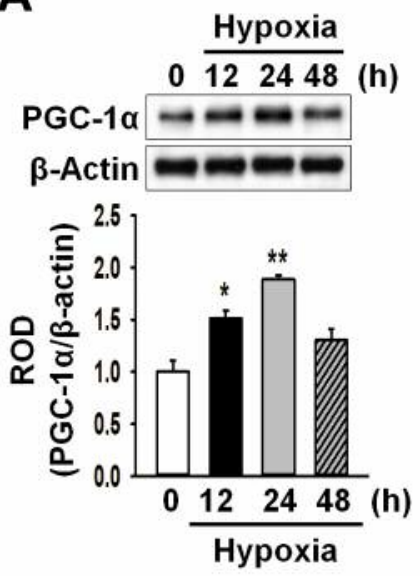

B

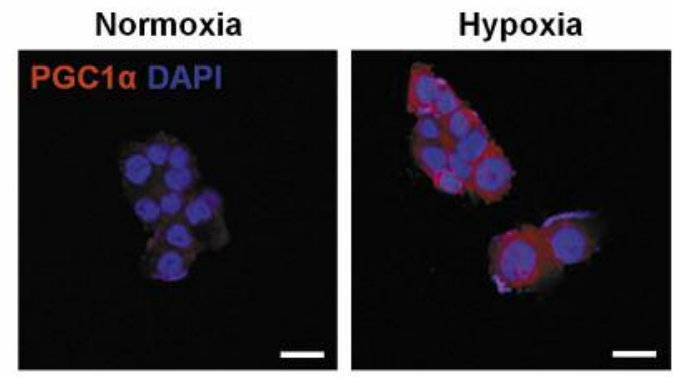

C

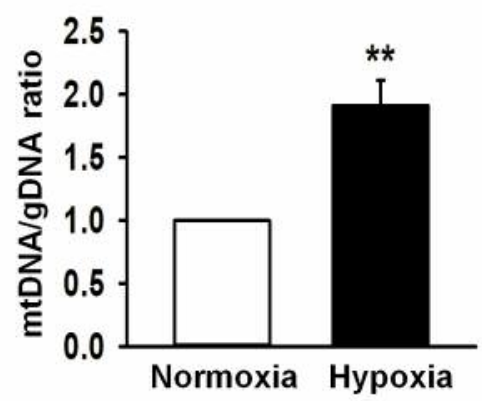

D

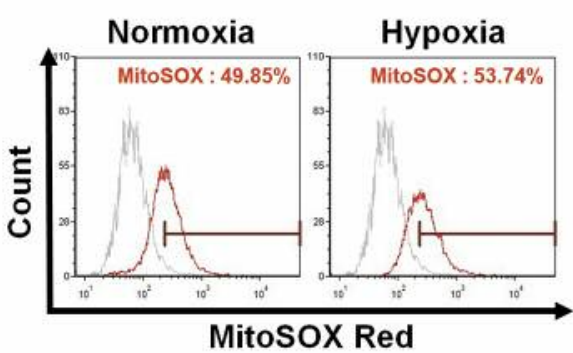

$\mathbf{E}$

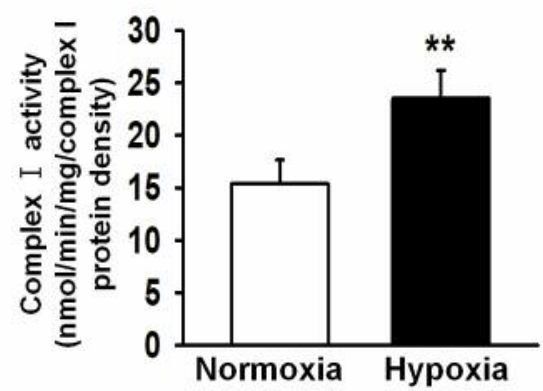

$\mathbf{F}$

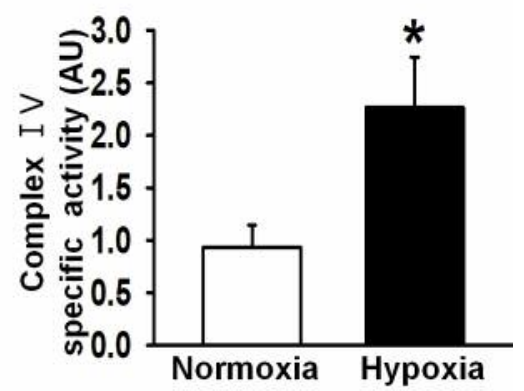

Figure 1. Effect of hypoxia on mitochondrial oxidative phosphorylation in colorectal cancer cells. (A) Expression of PGC-1 $\alpha$ in SNU-C5/WT cells under hypoxic conditions at various time points $(0,12,24$, and $48 \mathrm{~h})$. The expression level of PGC-1 $\alpha$ was determined relative to that of $\beta$-actin $(n=3)$. Values represent the mean $\pm S E M . * * p<0.01 \mathrm{vs}$. control. (B) Immunofluorescence staining for PGC-1 $\alpha$ (red) in SNU-C5/WT cells under normoxic or hypoxic conditions. Scale bar $=20 \mu \mathrm{m}$. (C) The ratio of mitochondrial DNA in SNU-C5/WT cells under normoxic or hypoxic conditions $(n=3)$. Values represent the mean $\pm S E M .{ }^{*} p<0.01$ vs. normoxia. (D) Flow cytometry analysis for MitoSOX in SNU-C5/WT cells under normoxic or hypoxic conditions. $(E$ and $F)$ The activity of mitochondrial complex $I(E)$ and $I V(F)$ in SNU-C5/WT cells under normoxic or hypoxic conditions $(n=3)$. Values represent the mean \pm SEM. ${ }^{*} p<0.05,{ }^{*} p<0.01 \mathrm{vs.} \mathrm{normoxia.}$

and $0.8 \mu \mathrm{M}$ antimycin, $\mathrm{pH}$ 7.4). Mitochondrial Complex I activity was measured using a Complex I Enzyme Activity Assay Kit (Abcam, Cambridge, UK), by following the manufacturer's instructions. The absorbance was determined from the rate of the oxidation of NADH $(100 \mathrm{mM})$ at $450 \mathrm{~nm}$ for every min up to $30 \mathrm{~min}$. Activity of the mitochondrial Complex IV was assessed using complex IV Enzyme Activity Kit (Abcam), by following the manufacturer's instructions.

Catalase and superoxide dismutase (SOD) activities. To assess the catalase activity, cell lysates of SNU-C5/WT cells were incubated with $20 \mathrm{mM} \mathrm{H}_{2} \mathrm{O}_{2}$ in $0.1 \mathrm{M}$ Tris-HCI (Sigma-Aldrich) for $30 \mathrm{~min}$ and then $50 \mathrm{mM}$ Amplex Red reagent (Thermo Fisher Scientific) and $0.2 \mathrm{U} / \mathrm{ml}$ of horseradish peroxidase (Sigma-Aldrich) were added; the mixture was subsequently incubated for $30 \mathrm{~min}$ at $37^{\circ} \mathrm{C}$ Alteration in the absorbance was quantified by recording the absorbance at $563 \mathrm{~nm}$ using a microplate reader. To measure SOD activity, cells were harvested from culture plates by scraping on ice.
The protein lysates were extracted using RIPA buffer. SOD activity was measured using a SOD activity kit (Enzo, Basel, Switzerland), by following the manufacturer's instructions.

Migration and invasion assay. To determine the migration of SNUC5/WT cells, wound-healing migration assay was performed. SNUC5/WT cells were cultured on $60 \mathrm{~mm}$ cell culture plate at $90 \%$ confluence in $4 \mathrm{ml}$ of growth medium. The cell layer was scratched by a $2 \mathrm{~mm}$ wide tip to establish a line-shaped wound. The cells were allowed to migrate and images were acquired by using an inverted microscope (Nikon, Tokyo, Japan). The invasion ability of SNU-C5/WT cells was measured using Matrigel-coated transwell cell culture chambers (8- $\mu$ m pore size; Merck Millipore, Billerica, MA, USA). The cells were first collected and resuspended in serum-free RPMI-1640 medium, and then $1 \times 10^{4}$ cells were seeded in the inserts of transwell chambers. Complete RPMI-1640 medium was added in the lower chamber. All samples were incubated for $48 \mathrm{~h}$ at $37^{\circ} \mathrm{C}$. In the transwell chambers, cells were immobilized with $4 \%$ paraformaldehyde in 
A
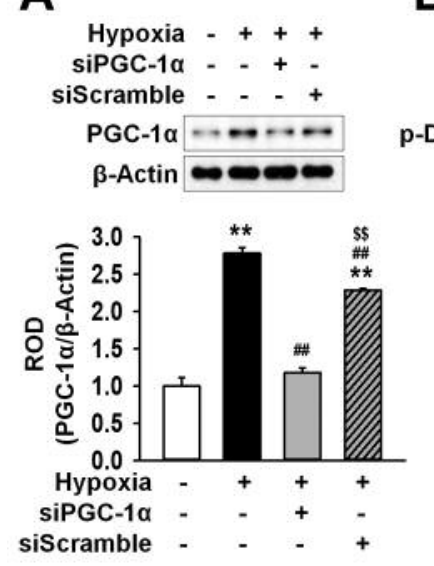

B

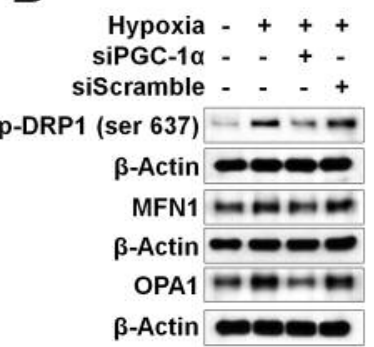

C

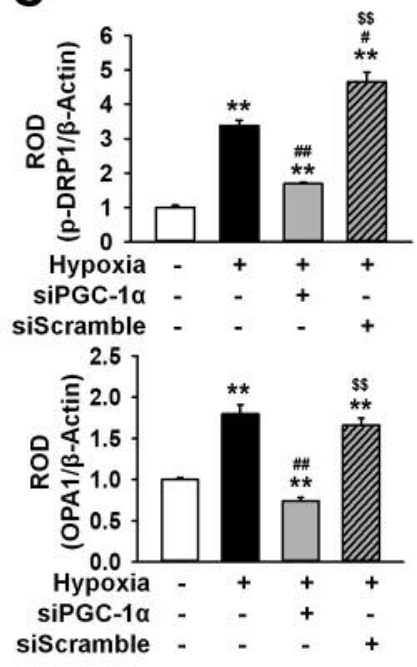

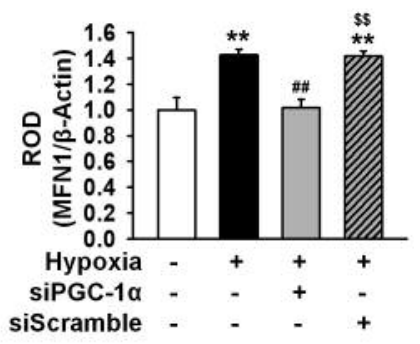

D

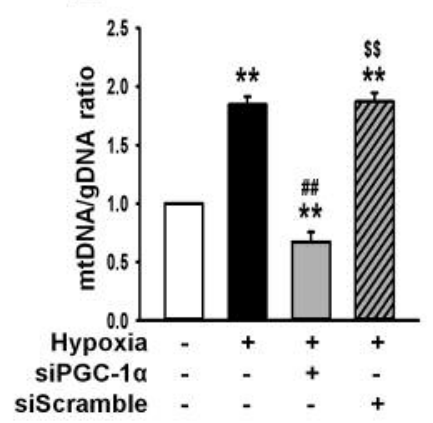

E

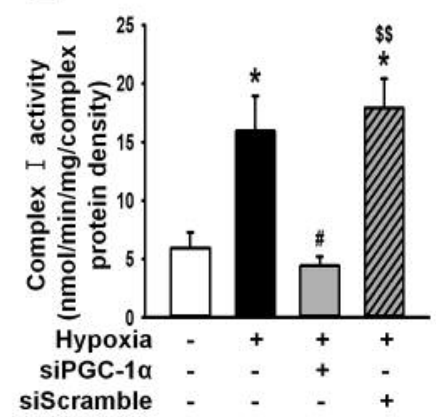

$F$

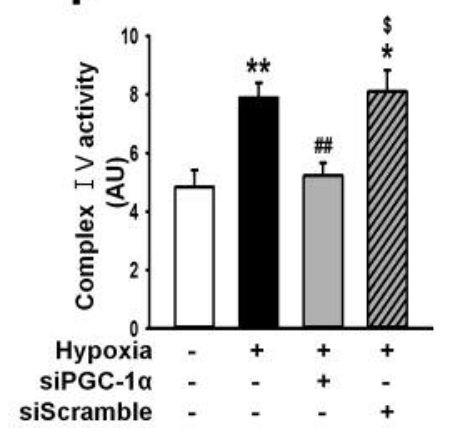

Figure 2. Hypoxia regulates mitochondrial biogenesis and oxidative phosphorylation in SNU-C5/WT cells through up-regulation of PGC-1 $\alpha$. (A) Post- PGC-1 $\alpha$ siRNA (siPGC-1 $\alpha$ )-transfection expression of PGC-1 $\alpha$ in SNU-C5/WT cells under hypoxic conditions for $24 \mathrm{~h}$. The expression level of PGC-1 $\alpha$ was determined relative to that of $\beta$-actin $(n=3)$. Values represent the mean $\pm S E M . * * p<0.01$ vs. normoxia, \#\#p<0.01 vs. hypoxia, $\$ \$ p<0.01$ vs. hypoxia+siPGC-1 $\alpha$. (B) Expression of $p-D R P 1$ (ser 637), MFN1, and OPA1 in SNU-C5/WT cells under hypoxic conditions for 24 h. (C) The expression levels of $p$-DRP1 (ser 637), MFN1, and OPA1 were determined relative to that of $\beta$-actin ( $n=3$ ). Values represent the mean $\pm S E M$. ${ }^{* *} p<0.01 \mathrm{vs}$. normoxia, ${ }^{\#} p<0.05,{ }^{\# \#} p<0.01 \mathrm{vs}$. hypoxia,${ }^{\$} \$ p<0.01$ vs hypoxia + siPGC-1 $\alpha$. (D) The ratio of mitochondrial DNA in SNU-C5/WT cells

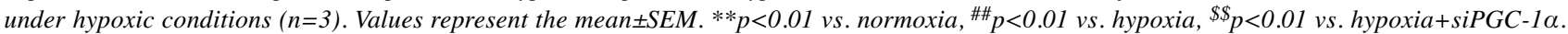
$(E$ and $F)$ The activity of mitochondrial complex $I(E)$ and $I V(F)$ in $S N U-C 5 / W T$ cells under hypoxic conditions ( $n=3)$. Values represent the mean \pm SEM. ${ }^{*} p<0.05, * * p<0.01$ vs. normoxia, ${ }^{\#} p<0.05$, ${ }^{*} p<0.01$ vs. hypoxia, ${ }_{p}<<0.05,{ }^{\$} \$ p<0.01$ vs. hypoxia + siPGC-1 $\alpha$.

phosphate-buffered saline and stained with $2 \%$ crystal violet in $2 \%$ ethanol. Lower surface of the transwell chamber contained invasive cells, which were quantified and photographed using a light microscope.

Tumor sphere formation assay. Tumor spheres were generated by seeding SNU-C5/WT cells (600 cells per well) in the Corning ${ }^{\circledR}$ Costar ${ }^{\circledR}$ Ultra-Low Attachment Multiple Well Plate (Sigma). Cells were preincubated under normoxia or hypoxia for $24 \mathrm{~h}$; they were subsequently grown in the plate for 14 days at $37^{\circ} \mathrm{C}$ with $5 \% \mathrm{CO}_{2}$ in a humidified incubator. An inverted microscope (Olympus, Tokyo, Japan) was used to capture images of the sphere formation at the end of 14 days.

Statistical analysis. Results are expressed as the mean \pm standard error of the mean (SEM). The significance between the groups was analyzed by a two-tailed student's $t$-test or by one-way analysis of variance. Data were considered significantly different at values of $p<0.05$.

\section{Results}

Hypoxia increases mitochondrial oxidative phosphorylation in CRC cells. Several studies have indicated that PGC- $1 \alpha$ is associated with mitochondrial biogenesis, respiration, and metabolism in many types of cancer cells (16-18). In addition, hypoxia induces PGC-1 $\alpha$ expression in breast cancer (19). To investigate the effect of hypoxia on PGC-1 $\alpha$ in CRC cells, the expression of PGC-1 $\alpha$ was assessed under hypoxic conditions at different time points $(0,12,24$, and $48 \mathrm{~h})$. After $24 \mathrm{~h}$ of hypoxia, the expression of PGC-1 $\alpha$ was significantly increased 


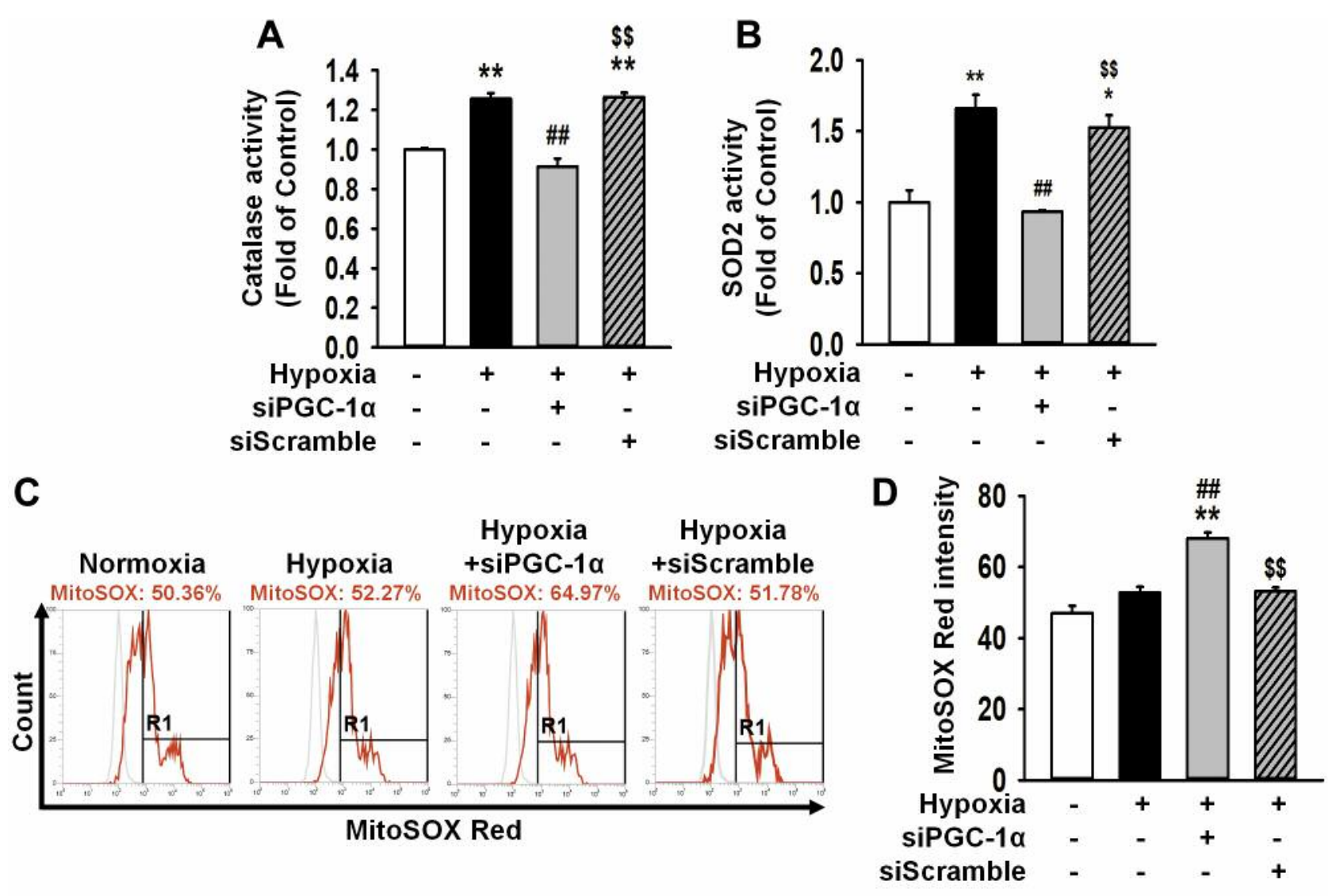

Figure 3. Anti-oxidant effect of hypoxia in SNU-C5/WT cells via induction of PGC-1 $\alpha$. (A and B) Activities of catalase (A) and SOD2 (B) in SNU$C 5 / W T$ cells transfected with siPGC-1 $\alpha$ under hypoxic conditions $(n=3)$. Values represent the mean $\pm S E M . * p<0.05$, **p<0.01 vs. normoxia, ${ }^{\# \#} p<0.01 \mathrm{vs}$. hypoxia, ${ }^{\$} \$ p<0.01 \mathrm{vs}$. hypoxia+siPGC-1 $\alpha$. (C) Flow cytometry analysis for MitoSOX in SNU-C5/WT cells transfected with siPGC-1 $\alpha$ under hypoxic conditions. (D) Production of mitochondrial ROS was quantified by MitoSOX positive cells ( $n=3)$. Values represent the mean $\pm S E M$.

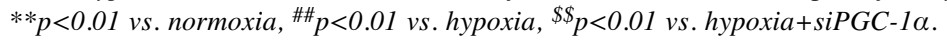

(Figure 1A). Immunofluorescence staining also showed a significant increase in the expression of PGC- $1 \alpha$ under hypoxic conditions (Figure 1B). The ratio of mitochondrial DNA/genomic DNA was significantly increased in hypoxia as compared with normoxia (Figure 1C). Although ROS generation was increased in hypoxia compared to normoxia, there was no significant difference between hypoxic and normoxic conditions (Figure 1D). Mitochondrial oxidative phosphorylation, including mitochondria complex I and IV activities, was significantly augmented in hypoxia as compared to normoxia (Figure $1 \mathrm{E}$ and $1 \mathrm{~F}$ ). These findings suggest that hypoxia increases mitochondrial oxidative phosphorylation through the up-regulation of PGC-1 $\alpha$ expression.

$P G C-1 \alpha$ regulates mitochondrial biogenesis and oxidative phosphorylation in CRC cells. To determine whether hypoxia regulates mitochondrial function in CRC cells via PGC- $1 \alpha$ levels, we silenced the expression of PGC-1 $\alpha$ (Figure 2A) in SNU-C5/WT cells and assessed the expression of mitochondrial fusion-associated proteins such as p-DRP1,
MFN1, and OPA1 (Figure 2B). Under hypoxic conditions, the levels of these proteins were significantly increased, whereas silencing of PGC-1 $\alpha$ blocked the augmentation of mitochondrial fusion-associated proteins by hypoxia (Figure 2C). In addition, the ratio of mitochondrial DNA/genomic DNA was significantly higher in hypoxia than that in normoxia, whereas knockdown of PGC-1 $\alpha$ significantly decreased the ratio of mitochondrial DNA under hypoxic conditions (Figure 2D). Mitochondrial oxidative phosphorylation, including mitochondrial complex I and IV activities, showed a significant increase in hypoxia as compared to normoxia; this effect was blocked by silencing of PGC-1 $\alpha$ (Figure $2 \mathrm{E}$ and F). These results indicate that under hypoxic conditions, $\mathrm{PGC}-1 \alpha$ regulates mitochondrial biogenesis and oxidative phosphorylation in CRC cells.

Antioxidant effect of PGC-1 $\alpha$ in CRC cells under hypoxic conditions. To verify whether hypoxia-induced PGC-1 $\alpha$ affects the antioxidant potential in CRC cells, activities of 


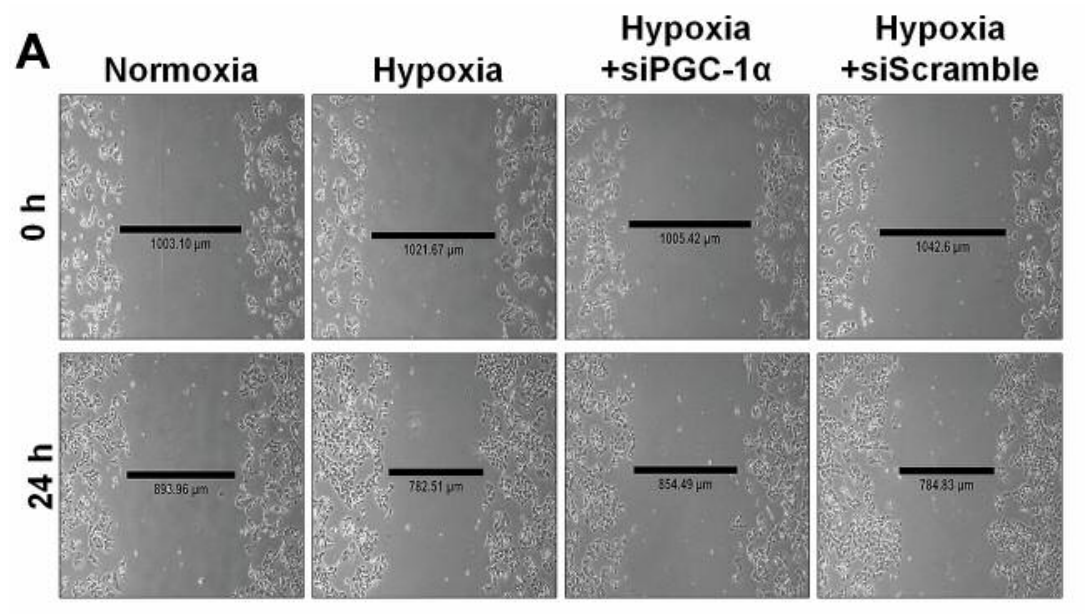

B
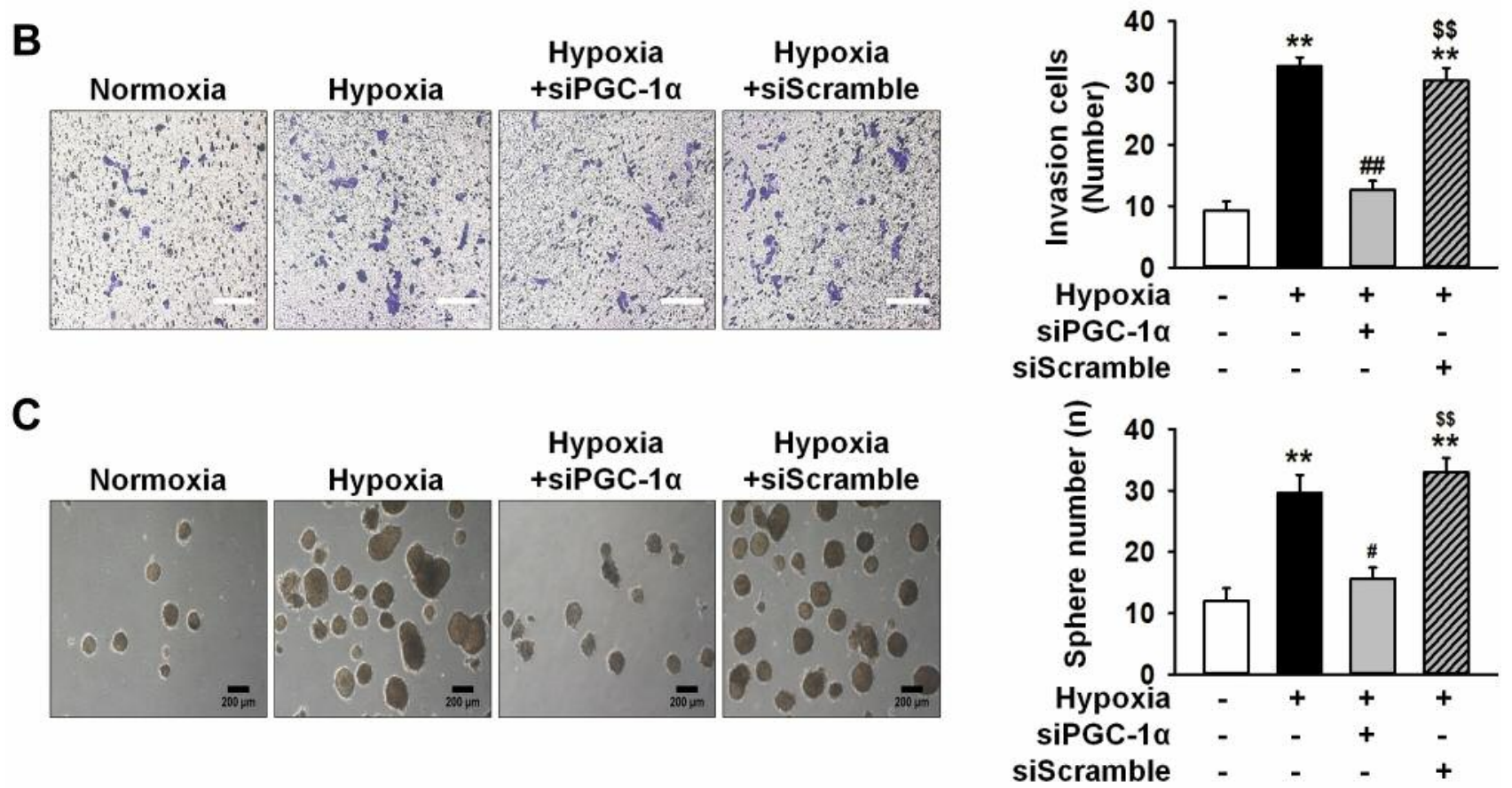

Figure 4. Effect of hypoxia on cancer mobility and sphere formation in SNU-C5/WT cells through the regulation of PGC-1 $\alpha$ expression. (A) Woundhealing migration assay in SNU-C5/WT cells under hypoxic condition. (B) Distance covered by migrated SNU-C5/WT cells $(n=3)$. Values represent the mean \pm SEM. $* * p<0.01$ vs. starting point $(0 h)$ in each group, \# ${ }^{*}<0.01$ vs. normoxia $(24 h), \$ \$ p<0.01$ vs hypoxia $(24 h)$, \& $p<0.05$ vs. hypoxia+siPGC-1 $\alpha(24 \mathrm{~h})$. (C) Invasion assay in SNU-C5/WT cells under hypoxic conditions. Invasive cells were stained by crystal violet (blue). (D) The number of invasive cells under hypoxic conditions $(n=3)$. Values represent the mean \pm SEM. $* * p<0.01$ vs. normoxia, \#\# $p<0.01$ vs. hypoxia, $\$ \$ p<0.01$ vs. hypoxia + siPGC-1 $\alpha$. (E) Formation of sphere in SNU-C5/WT cells under hypoxic conditions. $(F)$ The number of spheres of SNU-C5/WT

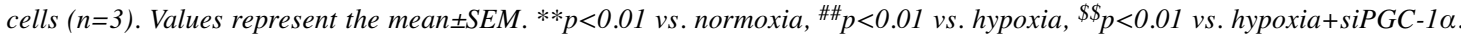

antioxidant enzymes in SNU-C5/WT cells were assessed under hypoxic conditions. Catalase and SOD2 activities were significantly increased in hypoxia as compared to normoxia; however, down-regulation of PGC- $1 \alpha$ significantly decreased the activities of antioxidant enzymes (Figure 3A and B). Hypoxia did not significantly increase the generation of ROS, whereas knockdown of PGC-1 $\alpha$ significantly increased the production of ROS under hypoxic conditions (Figure 3C and D). These findings suggest that hypoxia-induced PGC$1 \alpha$ controls the generation of ROS through the augmentation of the antioxidant enzyme activity.

Hypoxia induces mobility and tumorigenesis of CRC cells via $P G C-1 \alpha$. The capacity of migration and invasion of CRC 
A

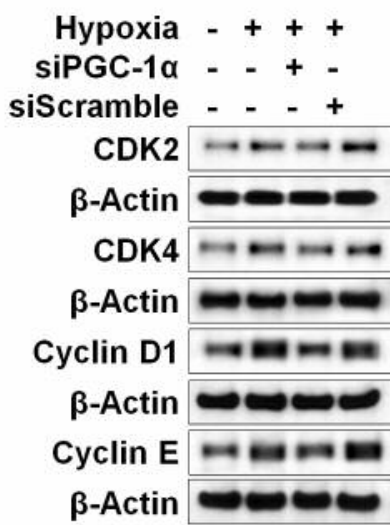

B
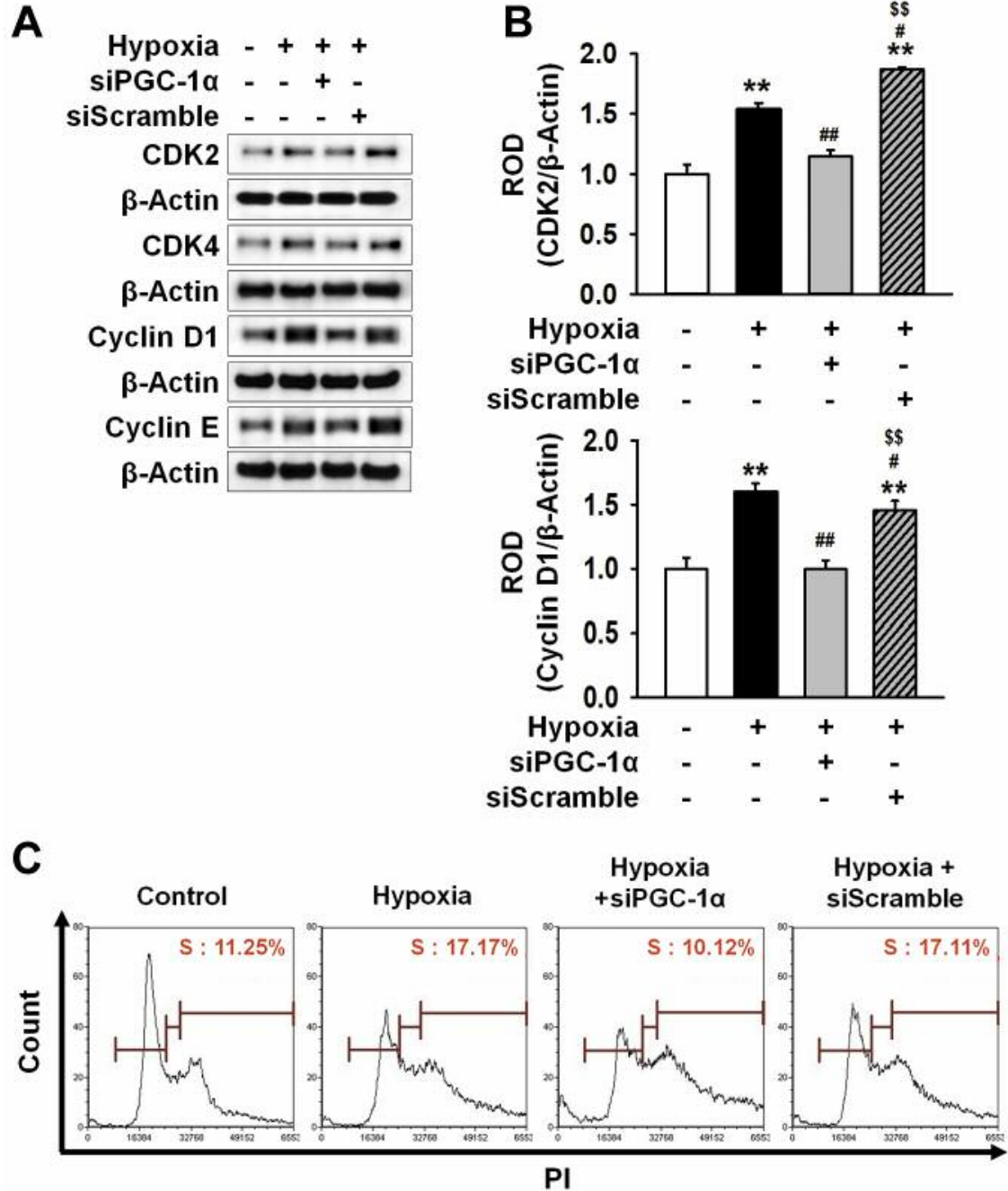
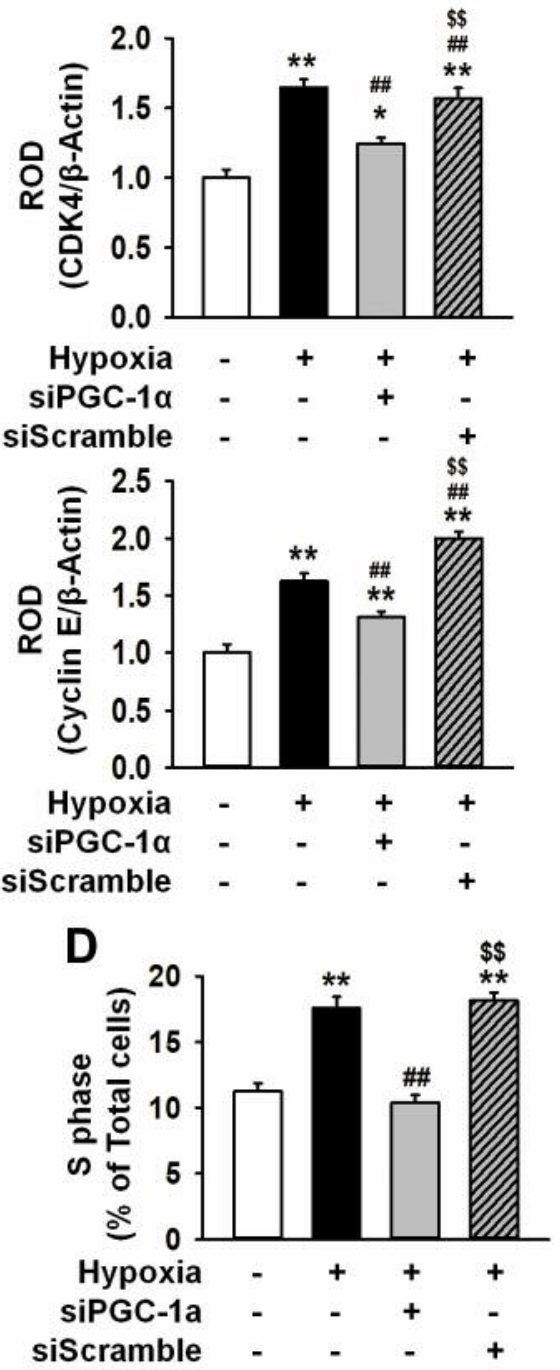

Figure 5. Hypoxia-induced PGC-1 $\alpha$ enhances the proliferation of SNU-C5/WT cells. (A) Expression of CDK2, CDK4, cyclin D1, and cyclin E in $S N U-C 5 / W T$ cells under hypoxic conditions. (B) The expression levels of CDK2, CDK4, cyclin D1, and cyclin E were determined relative to that of

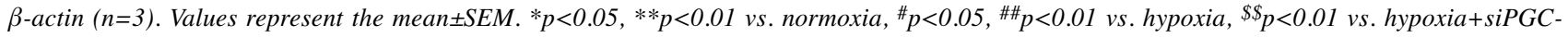
$1 \alpha .(C)$ Flow cytometry analysis for PI staining in SNU-C5/WT cells under hypoxic conditions. (D) The percentage of SNU-C5/WT cells in $S$ phase,

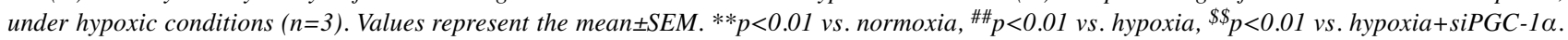

cells plays a pivotal role in metastasis and tumor remodeling. To determine the effect of PGC-1 $\alpha$ on the mobility of CRC cells under hypoxic conditions, migration and invasion capacities of SNU-C5/WT cells were examined. Wound scratch healing assay showed that the migration of cells was significantly higher in hypoxia as compared with normoxia. Furthermore, the silencing of PGC- $1 \alpha$ inhibited hypoxiainduced migration of cells (Figure 4A and B). Invasion capacity of cells was also significantly increased in hypoxia, however, knockdown of PGC-1 $\alpha$ blocked this effect (Figure $4 \mathrm{C}$ and D). To further investigate the effect of PGC- $1 \alpha$ on tumorigenesis of CRC cells under hypoxic conditions, we assessed the formation of SNU-C5/WT cell spheroid (Figure $4 \mathrm{E})$. The number of spheroids was significantly higher in hypoxia as compared to that in normoxia, whereas the sphere formation capacity of cells was significantly decreased by the down-regulation of PGC- $1 \alpha$ under hypoxic conditions (Figure 4F). These results indicate that hypoxia augments the mobility and tumorigenesis of CRC cells through the expression of PGC-1 $\alpha$.

Hypoxia facilitates the proliferation of CRC cells via PGC$1 \alpha$. To investigate the effect of hypoxia on the proliferation of CRC cells through the regulation of PGC- $1 \alpha$, we assessed 
A

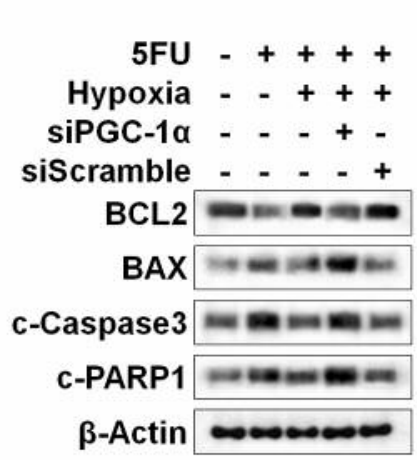

B
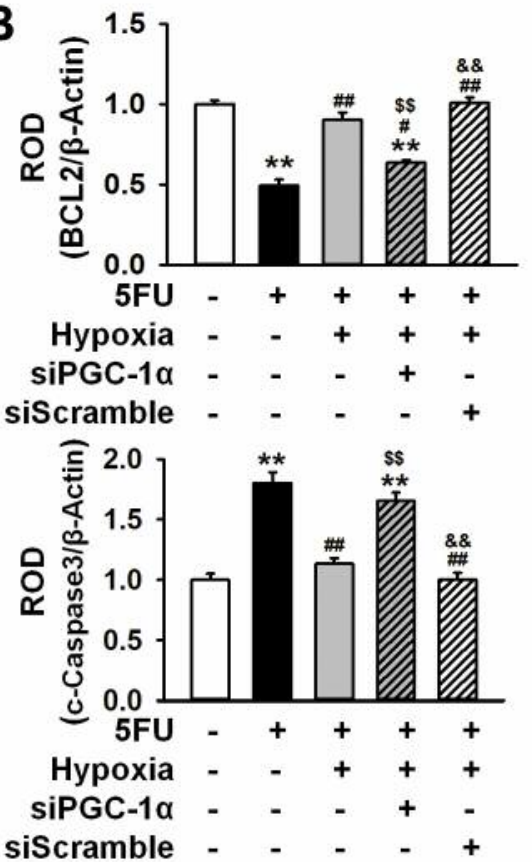
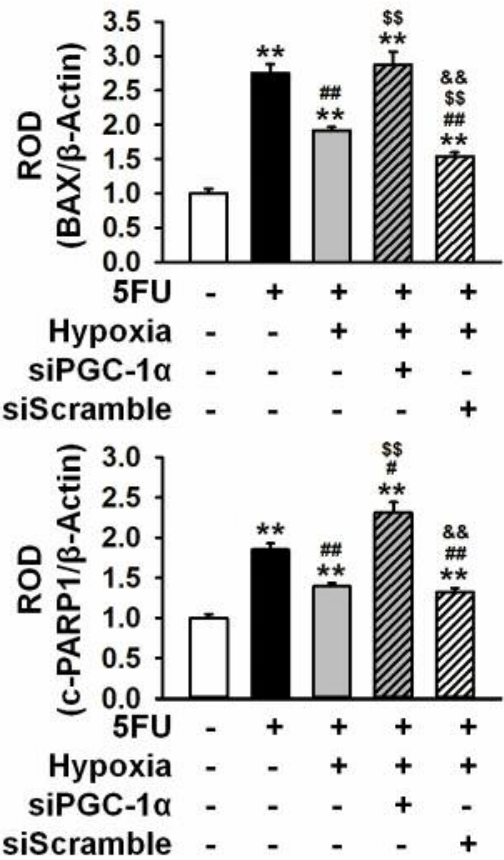

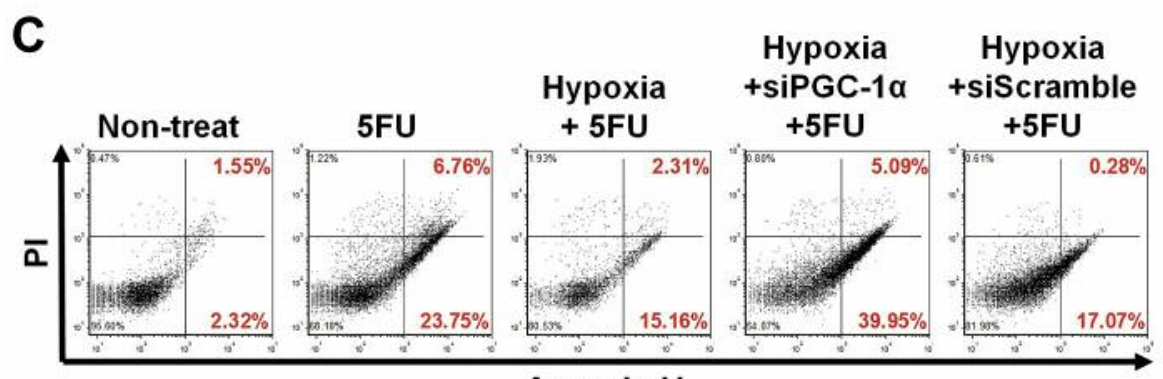

Annexin V
D

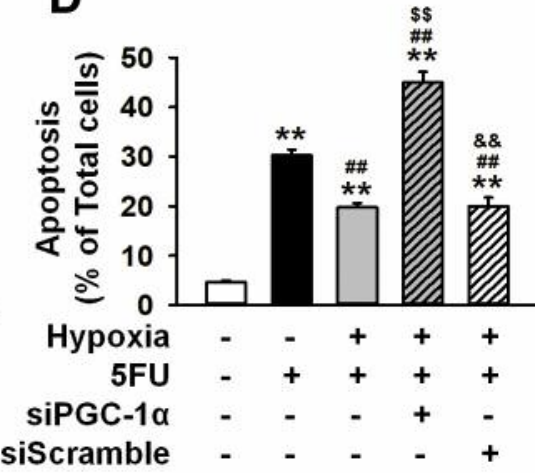

Figure 6. Hypoxia protects SNU-C5/WT cells against 5FU-induced apoptosis. (A) After treatment with 5FU, expression of BCL2, BAX, cleaved caspase-3 (c-Caspase3), and cleaved PARP1 (c-PARP1) in SNU-C5/WT cells under hypoxic conditions. (B) The expression levels of BCL2, BAX, $c$-Caspase 3 , and c-PARP1 were determined relative to that of $\beta$-actin $(n=3)$. Values represent the mean $\pm S E M .{ }^{*} * p<0.01 v s$. normoxia, ${ }^{\#} p<0.05$, ${ }^{\# \#} p<0.01$ vs. $5 F U$-treated cells under normoxic conditions, $\$ \$ p<0.01$ vs. $5 F U+$ hypoxia, \&\& $p<0.05$ vs. $5 F U+$ hypoxia + siPGC-1 $\alpha$. (C) After the treatment with 5FU, flow cytometry analysis for PI and Annexin V double staining in SNU-C5/WT cells under hypoxic conditions. (D) The percentage of apoptotic cells $(n=3)$. Values represent the mean $\pm S E M . * * p<0.01 \mathrm{vs}$. normoxia, ${ }^{* \#} p<0.01 \mathrm{vs}$. $5 F U$-treated cells under normoxic conditions, $\$ \$ p<0.01$ vs. $5 F U+$ hypoxia, \&\& $p<0.05$ vs. $5 F U+$ hypoxia + siPGC $-1 \alpha$.

the levels of cell cycle-associated proteins using western blot analysis (Figure 5A). The expression of CDK2, CDK4, cyclin D1, and cyclin E was significantly increased under hypoxic conditions (Figure 5B). However, knockdown of PGC- $1 \alpha$ significantly decreased the levels of cell cycleassociated proteins under hypoxic conditions (Figure 5B). Flow cytometry analysis using PI staining showed that hypoxia significantly increased the percentage of cells in $S$ phase as compared to that in normoxia; whereas, the silencing of PGC- $1 \alpha$ significantly inhibited the ratio of $\mathrm{S}$ phase (Figure 5C and 5D). These results indicate that hypoxia induces the proliferation of CRC cells through the increase in PGC-1 $\alpha$ level.

Hypoxia induces drug resistance in CRC cells through the up-regulation of $P G C-1 \alpha$. To examine whether hypoxia protects $\mathrm{CRC}$ cells against the treatment with anti-cancer drugs by regulating the expression of PGC-1a, we silenced 


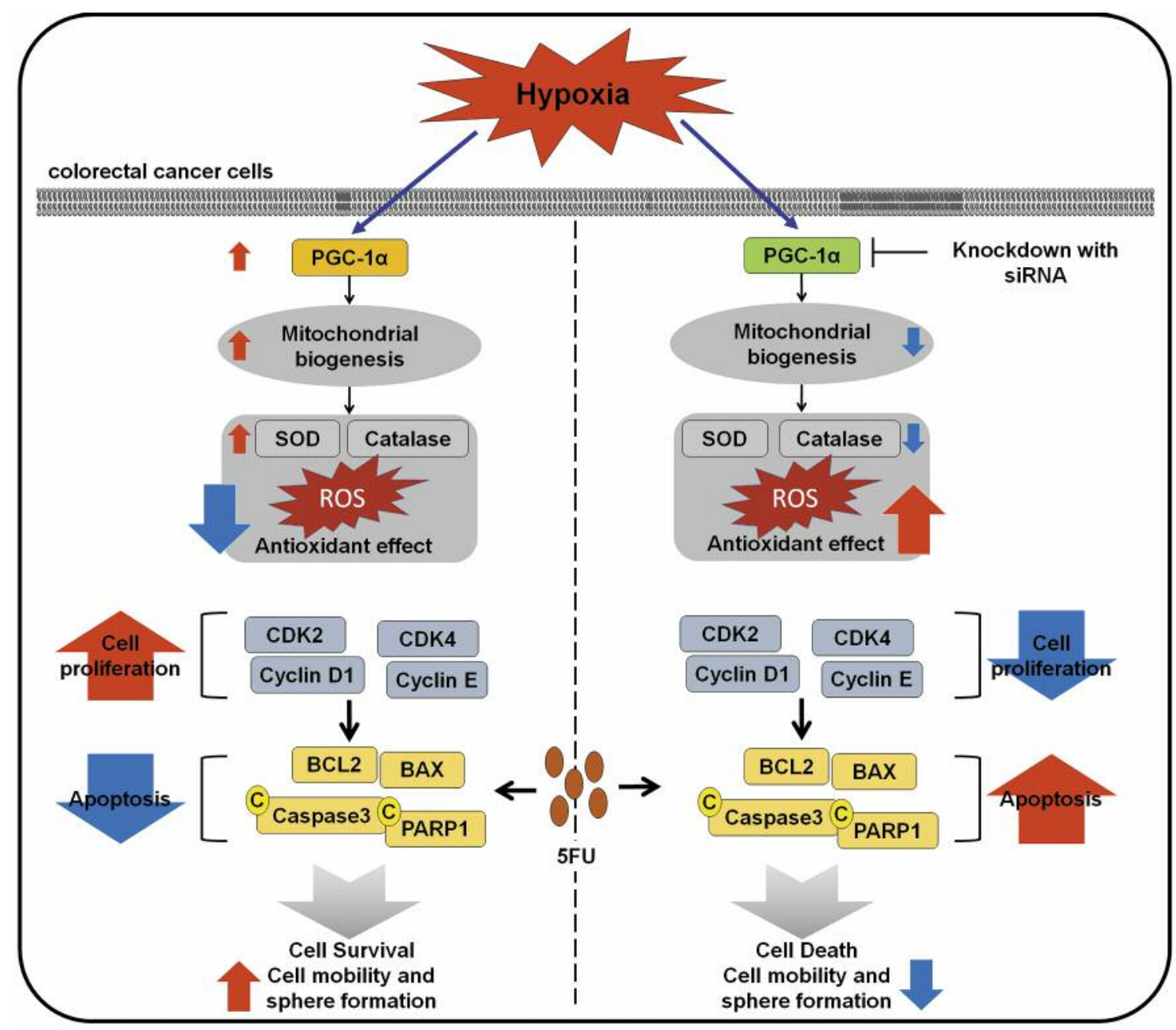

Figure 7. Schematic illustrating the mechanism by which hypoxia enhances mitochondrial biogenesis, activity of anti-oxidant enzymes, proliferation, and inhibition of apoptosis in a colorectal cancer cell through the augmentation of $P G C-1 \alpha$ level. In CRC cells, hypoxia increases the expression of PGC-1 $\alpha$, resulting in increase in mitochondrial biogenesis, mitochondrial oxidative phosphorylation, activity of SOD and catalase, and cell proliferation. In addition, hypoxia protects CRC cells against $5 F U$-induced apoptosis through the up-regulation of PGC-1 $\alpha$. However, knockdown of PGC-1 $\alpha$ blocked these effects under hypoxic conditions. These findings suggest that hypoxia-induced PGC-1 $\alpha$ regulates the mitochondrial function, cancer tumorigenesis, and anti-cancer drug sensitivity in CRC cells.

its expression in SNU-C5/WT cells and assessed the effect of hypoxia on their drug sensitivity. Initially, SNU-C5/WT cells were treated with 5FU and the expression of apoptosisassociated proteins was analyzed by western blot (Figure 6A). The levels of anti-apoptotic protein, BCL2, were significantly decreased during treatment with $5 \mathrm{FU}$ under normoxic conditions as compared with control. The levels of pro-apoptotic proteins including BAX, cleaved caspase-3, and cleaved PARP-1, were significantly increased during the treatment with $5 \mathrm{FU}$ under normoxic conditions as compared with control (Figure 6A and B). In the presence of 5FU, hypoxia significantly increased the expression of BCL2 and decreased the expression of BAX, cleaved caspase-3, and cleaved PARP-1 as compared to those in normoxia (Figure $6 \mathrm{~A}$ and $\mathrm{B}$ ). However, in the presence of $5 \mathrm{FU}$, silencing of PGC-1 $\alpha$ significantly blocked the hypoxia-induced protective effect against 5FU-mediated apoptosis (Figure 6A and B). Flow cytometry analysis using PI and Annexin V double staining showed that hypoxia significantly inhibited 5FU-mediated apoptosis in SNU-C5/WT cells; however, knockdown of PGC-1 $\alpha$ significantly induced 5FU-mediated apoptosis under hypoxia (Figure 6C and D). These findings revealed that hypoxia suppressed 5FU-mediated apoptosis in SNU-C5/WT cells, suggesting that hypoxia might induce resistance to 5FU in CRC cells via the regulation of PGC$1 \alpha$ expression. 


\section{Discussion}

This study indicated that hypoxia increased the expression of PGC- $1 \alpha$, leading to augmentation of mitochondrial biogenesis, mitochondrial oxidative phosphorylation, antioxidant enzyme expression, migration, invasion, sphere formation, and proliferation as well as the inhibition of apoptosis caused by the anti-cancer drug 5FU in CRC cells. Although HIF is generally known as a master transcription factor in cancer proliferation and metastasis under hypoxic conditions, our results indicate that PGC- $1 \alpha$ is also a central regulator of mitochondrial function, metastasis, proliferation, and apoptosis caused by 5FU treatment in CRC cells. These finding suggests that PGC- $1 \alpha$ might be a key molecule responsible for the regulation of $\mathrm{CRC}$ metabolism and tumorigenesis in response to hypoxia.

Human cancer is characterized by hypoxia. When the size of the tumor increases beyond 2-3 $\mathrm{mm}^{3}$ without neovascularization, it results in a hypoxic microenvironment (20). Cancer cells generally respond to hypoxia through activation of various signaling pathways for enhancing bioactivities (21). Among several signaling pathways, the HIF-mediated signaling pathway is important for cancer biology under hypoxic conditions. HIF-1 plays a pivotal role in the adaptation to hypoxia. Under hypoxia, HIF-1 $\alpha$ is stabilized and binds to HIF-1 $\beta$, resulting in the complex of HIF-1 $\alpha$ with HIF-1 $\beta$; this complex works as a transcription factor and regulates numerous target genes involved in survival, proliferation, energy metabolism, apoptosis, tumor vascularization, and metastasis $(22,23)$. Under hypoxia, HIF-1 $\alpha$ enhances the cellular adaptation to hypoxia through the interaction with $\beta$-catenin, resulting in increased survival of CRC cells (24). HIF-1 $\alpha$ induces shift reprograming of energy metabolism from aerobic mitochondrial respiration to anaerobic glycolysis through the phosphorylation of pyruvate dehydrogenase, inhibition of activity of pyruvate dehydrogenase, and activation of lactate dehydrogenase A (25). HIF-1 $\alpha$ also increases the expression of vascular endothelial growth factor (VEGF) by binding to the HRE regions of VEGF promoters in CRC cells (26). In addition, hypoxia regulates the epithelial-mesenchymal transitionassociated genes such as cathepsin D, matrix metalloproteinase 2 , fibronectin 1 , keratin, vimentin, and transforming growth factor $\alpha$ by up-regulating HIF- $1 \alpha$ in CRC cells (27). Furthermore, hypoxia protects CRC cells against treatment with anti-cancer drug via multidrug resistance protein 1/ATP-binding cassette super-family G member 2 signal axis (28). In this study, we showed that hypoxia enhances mitochondrial energy metabolism, antioxidant enzyme expression, migration, invasion, sphere formation, proliferation, and drug-resistance in CRC cells. We did not focus on HIF-dependent signaling pathway under hypoxic conditions, but rather focused on PGC-1 $\alpha$ - dependent signaling pathway for enhancing cancer cell bioactivities. A recent review article indicated that PGC-1 $\alpha$ expression is not dependent on the activation of HIF-1, since various methods for activation of HIF-1 fail to induce the expression of PGC-1 $\alpha$ (29). These results suggest that PGC$1 \alpha$ signaling pathway might be independent of HIF-1. However, the relation between HIF-1 and PGC- $1 \alpha$ needs to be investigated further.

PGC- $1 \alpha$ is a powerful regulator of mitochondrial biogenesis and mitochondrial metabolism in various cell types. PGC- $1 \alpha$ is regulated by AMP-activated protein kinase signaling pathway, which recognizes the level of cellular AMP. In response to fasting, activation of PGC- $1 \alpha$ by AMPK increases the expression of genes involved in gluconeogenesis and beta oxidation in liver (30). PGC-1 $\alpha$ knockout mice showed dysfunctions in cardiac mitochondria and energy metabolism (31-33). PGC-1 $\alpha$ facilitates the amount of mitochondrial DNA, leading to the induction of several genes involved in mitochondrial oxidative phosphorylation such as ATP synthase, cytochrome c, cytochrome $\mathrm{c}$ oxidase subunits, transcription factor $\mathrm{A}$ mitochondrial, and transcription factor B1/B2M (10). Furthermore, PGC- $1 \alpha$ is associated with the regulation of glucose metabolism by inducing the expression of glucose transporter 4, resulting in the augmentation of glucose uptake (34). Our results showed that hypoxia-induced PGC-1 $\alpha$ significantly increased the amount of mitochondrial DNA, mitochondrial oxidative phosphorylation, mitochondrial fusion-associated proteins including p-DRP1, MFN1, and OPA1 as well as mitochondrial anti-oxidant enzyme activity. These findings suggest that PGC- $1 \alpha$ is a key regulator of CRC mitochondrial biogenesis and metabolism under hypoxic conditions.

Recent studies have shown that PGC- $1 \alpha$ contributes to cancer survival, proliferation, metastasis, and inhibition of apoptosis $(35,36)$. In melanoma cells, overexpression of PGC$1 \alpha$ showed a significant increase in the proliferation and survival of cancer cells, whereas low level of PGC- $1 \alpha$ decreased the amount of mitochondria, proliferation, and survival against ROS-induced apoptosis (35-37). In epithelial cancer cells, elevated PGC-1 $\alpha$ level facilitated mitochondrial biogenesis, invasive capacity, and metastasis potential, inducing cancer cell metastasis (16). In addition, enhanced level of PGC-1 $\alpha$ in melanoma cells increased chemoresistance by elevated mitochondrial oxidative metabolism (38). Similar to these findings, our results showed that hypoxia-induced PGC-1 $\alpha$ expression in CRC cells increased migration ability, invasion capacity, formation of tumor sphere, expression of cell cycle-associated proteins including CDK2, CDK4, cyclin D1, and cyclin $\mathrm{E}$, proliferation, and resistance against 5FU-induced apoptosis. These findings suggest that PGC- $1 \alpha$ regulates CRC bioactivities such as proliferation, metastasis, and drug resistance, under hypoxia. 
Taken together, we revealed that hypoxia induced the expression of PGC-1 $\alpha$ in CRC cells and hypoxia-induced PGC$1 \alpha$ regulated mitochondrial biogenesis, mitochondrial oxidative metabolism, anti-oxidant enzyme activity, proliferation, migration and invasion capacity, tumorigenesis, and anti-cancer drug resistance in CRC cells (Figure 7). In particular, silencing of PGC-1 $\alpha$ blocked these effects in CRC cells under hypoxia, suggesting that PGC- $1 \alpha$ could be a potential target for CRC therapy. However, hypoxia also promotes the expression of HIF- $1 \alpha$ as that of PGC- $1 \alpha$. Therefore, future studies need to investigate the relation between HIF- $1 \alpha$ and PGC- $1 \alpha$ and their dual targeting for CRC therapy.

\section{Conflicts of Interest}

The Authors have no conflicts of interest to declare with regards to this study.

\section{Authors' Contributions}

Chul Won Yun: data collection and drafting of manuscript; Jun Hee Lee: data analysis and drafting of manuscript; Sang Hun Lee: organizing the structure of the manuscript, drafting and editing of the manuscript, procurement of funding.

\section{Acknowledgements}

This study was supported by a National Research Foundation grant funded by the Korean government (NRF-2016R1D1A3B01007727 and NRF-2017M3A9B4032528). The funders of the grant played no roles in the manuscript design, decision to publish or preparation of the manuscript.

\section{References}

1 Markowitz SD and Bertagnolli MM: Molecular origins of cancer: Molecular basis of colorectal cancer. N Engl J Med 361(25): 2449-2460, 2009. PMID: 20018966. DOI: 10.1056/NEJ Mra0804588

2 D'Ignazio L, Batie M and Rocha S: Hypoxia and inflammation in cancer, focus on hif and nf-kappab. Biomedicines 5(2), 2017. PMID: 28536364. DOI: 10.3390/biomedicines5020021

3 Semenza GL: Oxygen homeostasis. Wiley Interdiscip Rev Syst Biol Med 2(3): 336-361, 2010. PMID: 20836033. DOI: 10.1002/ wsbm.69

4 Harris AL: Hypoxia - a key regulatory factor in tumour growth. Nat Rev Cancer 2(1): 38-47, 2002. PMID: 11902584. DOI: $10.1038 / \mathrm{nrc} 704$

5 Munoz-Pinedo C, El Mjiyad N and Ricci JE: Cancer metabolism: Current perspectives and future directions. Cell Death Dis 3: e248, 2012. PMID: 22237205. DOI: $10.1038 /$ cddis.2011.123

6 Vaupel P and Mayer A: Hypoxia in cancer: Significance and impact on clinical outcome. Cancer Metastasis Rev 26(2): 225239, 2007. PMID: 17440684. DOI: 10.1007/s10555-007-9055-1

7 Vadde R, Vemula S, Jinka R, Merchant N, Bramhachari PV and Nagaraju GP: Role of hypoxia-inducible factors (hif) in the maintenance of stemness and malignancy of colorectal cancer.
Crit Rev Oncol Hematol 113: 22-27, 2017. PMID: 28427511. DOI: $10.1016 /$ j.critrevonc.2017.02.025

8 Nagaraju GP, Bramhachari PV, Raghu G and El-Rayes BF: Hypoxia inducible factor-1alpha: Its role in colorectal carcinogenesis and metastasis. Cancer Lett 366(1): 11-18, 2015. PMID: 26116902. DOI: 10.1002/wsbm.69

9 Gordan JD, Thompson CB and Simon MC: Hif and c-myc: Sibling rivals for control of cancer cell metabolism and proliferation. Cancer Cell 12(2): 108-113, 2007. PMID: 2083 6033. DOI: $10.1016 /$ j.canlet.2015.06.005

10 Bost $\mathrm{F}$ and Kaminski L: The metabolic modulator pgc-1alpha in cancer. Am J Cancer Res 9(2): 198-211, 2019. PMID: 30906622.

11 Schreiber SN, Emter R, Hock MB, Knutti D, Cardenas J, Podvinec M, Oakeley EJ and Kralli A: The estrogen-related receptor alpha (erralpha) functions in ppargamma coactivator 1alpha (pgc-1alpha)-induced mitochondrial biogenesis. Proc Natl Acad Sci USA 101(17): 6472-6477, 2004. PMID: 15087503. DOI: 10.1073 /pnas.0308686101

12 Napal L, Marrero PF and Haro D: An intronic peroxisome proliferator-activated receptor-binding sequence mediates fatty acid induction of the human carnitine palmitoyltransferase 1a. J Mol Biol 354(4): 751-759, 2005. PMID: 16271724. DOI: 10.1016/j.jmb.2005.09.097

13 St-Pierre J, Drori S, Uldry M, Silvaggi JM, Rhee J, Jager S, Handschin C, Zheng K, Lin J, Yang W, Simon DK, Bachoo R and Spiegelman BM: Suppression of reactive oxygen species and neurodegeneration by the pgc-1 transcriptional coactivators. Cell 127(2): 397-408, 2006. PMID: 17055439. DOI: 10.1016/ j.cell.2006.09.024

14 Liou GY and Storz P: Reactive oxygen species in cancer. Free Radic Res 44(5): 479-496, 2010. PMID: 20370557. DOI: $10.3109 / 10715761003667554$

15 Wang YY, Attane C, Milhas D, Dirat B, Dauvillier S, Guerard A, Gilhodes J, Lazar I, Alet N, Laurent V, Le Gonidec S, Biard D, Herve C, Bost F, Ren GS, Bono F, Escourrou G, Prentki M, Nieto L, Valet $\mathrm{P}$ and Muller C: Mammary adipocytes stimulate breast cancer invasion through metabolic remodeling of tumor cells. JCI Insight 2(4): e87489, 2017. PMID: 28239646. DOI: $10.1172 /$ jci.insight. 87489

16 LeBleu VS, O'Connell JT, Gonzalez Herrera KN, Wikman H, Pantel K, Haigis MC, de Carvalho FM, Damascena A, Domingos Chinen LT, Rocha RM, Asara JM and Kalluri R: Pgc1alpha mediates mitochondrial biogenesis and oxidative phosphorylation in cancer cells to promote metastasis. Nat Cell Biol 16(10): 992-1003, 1001-1015, 2014. PMID: 2524103. DOI: 10.1038/ncb3039

17 Koh E, Kim YK, Shin D and Kim KS: Mpc1 is essential for pgc1alpha-induced mitochondrial respiration and biogenesis. Biochem J 475(10): 1687-1699, 2018. PMID: 29669911. DOI: 10.1042/BCJ20170967

18 Yun CW, Han YS and Lee SH: Pgc-1alpha controls mitochondrial biogenesis in drug-resistant colorectal cancer cells by regulating endoplasmic reticulum stress. Int J Mol Sci 20(7), 2019. PMID: 30959809. DOI: 10.3390/ijms20071707

19 Cai FF, Xu C, Pan X, Cai L, Lin XY, Chen S and Biskup E: Prognostic value of plasma levels of hif-1a and pgc-1a in breast cancer. Oncotarget 7(47): 77793-77806, 2016. PMID: 2778092. DOI: 10.18632 /oncotarget.12796

20 Zong S, Li W, Li H, Han S, Liu S, Shi Q and Hou F: Identification of hypoxia-regulated angiogenic genes in 
colorectal cancer. Biochem Biophys Res Commun 493(1): 461467, 2017. PMID: 28928094. DOI: 10.1016/j.bbrc.2017.08.169

21 Hockel M and Vaupel P: Tumor hypoxia: Definitions and current clinical, biologic, and molecular aspects. J Natl Cancer Inst 93(4): 266-276, 2001. PMID: 11181773. DOI: 10.1093/ jnci/93.4.266

22 Pugh CW, Tan CC, Jones RW and Ratcliffe PJ: Functional analysis of an oxygen-regulated transcriptional enhancer lying 3 ' to the mouse erythropoietin gene. Proc Natl Acad Sci USA 88(23): 10553-10557, 1991. PMID: 1961720. DOI: 10.1073/ pnas.88.23.10553

23 Semenza GL: Regulation of cancer cell metabolism by hypoxiainducible factor 1. Semin Cancer Biol 19(1): 12-16, 2009. PMID: 19114105. DOI: 10.1016/j.semcancer.2008.11.009

24 Kaidi A, Williams AC and Paraskeva C: Interaction between betacatenin and hif-1 promotes cellular adaptation to hypoxia. Nat Cell Biol 9(2): 210-217, 2007. PMID: 17220880. DOI: 10.1038/ncb1534

25 Zhao T, Zhu Y, Morinibu A, Kobayashi M, Shinomiya K, Itasaka S, Yoshimura M, Guo G, Hiraoka M and Harada H: Hif-1mediated metabolic reprogramming reduces ros levels and facilitates the metastatic colonization of cancers in lungs. Sci Rep 4: 3793, 2014. PMID: 24452734. DOI: 10.1038/srep03793

26 Cao D, Hou M, Guan YS, Jiang M, Yang Y and Gou HF: Expression of hif-1alpha and vegf in colorectal cancer: Association with clinical outcomes and prognostic implications. BMC Cancer 9: 432, 2009. PMID: 20003271. DOI: 10.1186/ 1471-2407-9-432

27 Krishnamachary B, Berg-Dixon S, Kelly B, Agani F, Feldser D, Ferreira G, Iyer N, LaRusch J, Pak B, Taghavi P and Semenza GL: Regulation of colon carcinoma cell invasion by hypoxia-inducible factor 1. Cancer Res 63(5): 1138-1143, 2003. PMID: 12615733.

28 Chen J, Ding Z, Peng Y, Pan F, Li J, Zou L, Zhang Y and Liang $\mathrm{H}$ : Hif-1alpha inhibition reverses multidrug resistance in colon cancer cells via downregulation of mdr1/p-glycoprotein. PLoS One 9(6): e98882, 2014. PMID: 24901645. DOI: 10.1371/ journal.pone.0098882

29 Shoag J and Arany Z: Regulation of hypoxia-inducible genes by pgc-1 alpha. Arterioscler Thromb Vasc Biol 30(4): 662-666, 2010. PMID: 19948845. DOI: 10.1161/ATVBAHA.108.181636

30 Yoon JC, Puigserver P, Chen G, Donovan J, Wu Z, Rhee J, Adelmant G, Stafford J, Kahn CR, Granner DK, Newgard CB and Spiegelman BM: Control of hepatic gluconeogenesis through the transcriptional coactivator pgc-1. Nature 413(6852): 131-138, 2001. PMID: 11557972. DOI: 10.1038/35093050

31 Arany Z, He H, Lin J, Hoyer K, Handschin C, Toka O, Ahmad F, Matsui T, Chin S, Wu PH, Rybkin, II, Shelton JM, Manieri M, Cinti S, Schoen FJ, Bassel-Duby R, Rosenzweig A, Ingwall JS and Spiegelman BM: Transcriptional coactivator pgc-1 alpha controls the energy state and contractile function of cardiac muscle. Cell Metab 1(4): 259-271, 2005. PMID: 16054070. DOI: $10.1016 /$ j.cmet.2005.03.002
32 Arany Z, Novikov M, Chin S, Ma Y, Rosenzweig A and Spiegelman BM: Transverse aortic constriction leads to accelerated heart failure in mice lacking ppar-gamma coactivator 1alpha. Proc Natl Acad Sci USA 103(26): 10086-10091, 2006. PMID: 1677508. DOI: 10.1073/pnas.0603615103

33 Lehman JJ, Boudina S, Banke NH, Sambandam N, Han X, Young DM, Leone TC, Gross RW, Lewandowski ED, Abel ED and Kelly DP: The transcriptional coactivator pgc-1alpha is essential for maximal and efficient cardiac mitochondrial fatty acid oxidation and lipid homeostasis. Am J Physiol Heart Circ Physiol 295(1): H185-196, 2008. PMID: 18487436. DOI: 10.1152/ajpheart.00081.2008

34 Michael LF, Wu Z, Cheatham RB, Puigserver P, Adelmant G, Lehman JJ, Kelly DP and Spiegelman BM: Restoration of insulin-sensitive glucose transporter (glut4) gene expression in muscle cells by the transcriptional coactivator pgc-1. Proc Natl Acad Sci USA 98(7): 3820-3825, 2001. PMID: 11274399. DOI: 10.1073/pnas.061035098

35 Luo C, Lim JH, Lee Y, Granter SR, Thomas A, Vazquez F, Widlund HR and Puigserver P: A pgclalpha-mediated transcriptional axis suppresses melanoma metastasis. Nature 537(7620): 422-426, 2016. PMID: 27580028. DOI: 10.1038/ nature 19347

36 Vazquez F, Lim JH, Chim H, Bhalla K, Girnun G, Pierce K, Clish CB, Granter SR, Widlund HR, Spiegelman BM and Puigserver P: Pgc1alpha expression defines a subset of human melanoma tumors with increased mitochondrial capacity and resistance to oxidative stress. Cancer Cell 23(3): 287-301, 2013. PMID: 23416000. DOI: 10.1016/j.ccr.2012.11.020

37 Piskounova E, Agathocleous M, Murphy MM, Hu Z, Huddlestun SE, Zhao Z, Leitch AM, Johnson TM, DeBerardinis RJ and Morrison SJ: Oxidative stress inhibits distant metastasis by human melanoma cells. Nature 527(7577): 186-191, 2015. PMID: 26466563. DOI: 10.1038/nature15726

38 Haq R, Shoag J, Andreu-Perez P, Yokoyama S, Edelman H, Rowe GC, Frederick DT, Hurley AD, Nellore A, Kung AL, Wargo JA, Song JS, Fisher DE, Arany Z and Widlund HR: Oncogenic braf regulates oxidative metabolism via pgc1alpha and mitf. Cancer Cell 23(3): 302-315, 2013. PMID: 23477830. DOI: $10.1016 /$ j.ccr.2013.02.003 